\title{
Maternal depression and socio-economic status moderate the parenting style/child obesity association
}

\author{
Glade L Topham ${ }^{1, *}$, Melanie C Page ${ }^{2}$, Laura Hubbs-Tait ${ }^{1}$, Julie M Rutledge ${ }^{1}$, \\ Tay S Kennedy ${ }^{3}$, Lenka Shriver ${ }^{3}$ and Amanda W Harrist ${ }^{1}$ \\ 'Department of Human Development and Family Science, 233 HES, Oklahoma State University, Stillwater, \\ OK 74078, USA: ${ }^{2}$ Department of Psychology, Oklahoma State University, Stillwater, OK, USA: ${ }^{3}$ Department of \\ Nutritional Sciences, Oklahoma State University, Stillwater, OK, USA
}

Submitted 31 December 2008: Accepted 20 October 2009: First published online 8 December 2009

\begin{abstract}
Objective: The purpose of the study was to test the moderating influence of two risk factors, maternal depression and socio-economic status (SES), on the association between authoritarian and permissive parenting styles and child obesity. Design: Correlational, cross-sectional study. Parenting style was measured with the Parenting Styles and Dimensions Questionnaire (PSDQ). Maternal depression was measured using the Center for Epidemiologic Studies Depression Scale (CESD). BMI-for-age percentile was used to categorize children by weight status (children with BMI-for-age $\geq 95$ th percentile were classified as obese). SES was computed from parent education and occupational status using the four-factor Hollingshead index.

Setting: Rural public schools in a mid-western state in the USA.

Subjects: One hundred and seventy-six mothers of first-grade children (ninety-one boys, eighty-five girls) enrolled in rural public schools.

Results: Both maternal depression and SES were found to moderate the permissive parenting style/child obesity association, but not the authoritarian/child obesity association. For depressed mothers, but not for non-depressed mothers, more permissive parenting was predictive of child obesity. Similarly more permissive parenting was predictive of child obesity among higher SES mothers, but not for lower SES mothers.

Conclusions: Maternal depression and SES interact with permissive parenting style to predict child obesity. Future research should examine the relationship among these variables using a longitudinal design.
\end{abstract}

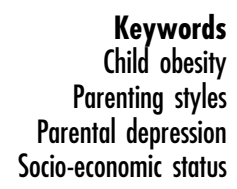

Keywords

Child obesity

Parental depression

Socio-economic status
Child obesity has become one of the top public health concerns in recent years ${ }^{(1,2)}$. The WHO has declared obesity to be a world epidemic ${ }^{(3)}$, with at least one in ten school-aged children worldwide meeting criteria for overweight $^{(4)}$. In the USA approximately one in six children between the ages of 2 and 19 years is obese and approximately one in three children is overweight ${ }^{(5)}$. A number of negative physical health consequences ${ }^{(6)}$ and psychosocial consequences $^{(7,8)}$ of childhood overweight and obesity have been well documented. The urgency of this public health problem has led to revisions in terminology such that children with BMI-for-age $\geq 95$ th percentile are designated 'obese' and children with BMIfor-age $\geq 85$ th percentile but $<95$ th percentile are classified as 'overweight' ${ }^{(9)}$. We follow this revised terminology in the current report.

Although numerous intervention programmes for childhood obesity have been developed in the last several decades, most have had limited success ${ }^{(10)}$. As a result, treatment providers have been encouraged to address broader contextual factors ${ }^{(11,12)}$ with specific attention to general, non-food-related, parenting ${ }^{(13,14)}$. In the past, research linking parenting to child obesity has focused on food-related parenting (e.g. determining portion sizes, encouraging/discouraging eating); only recently have researchers begun to look at more general parenting style in relation to child obesity ${ }^{(15)}$.

Baumrind $^{(16)}$ identified three different general parenting styles based on levels of parent control/demandingness and warmth/responsiveness. Authoritarian parents are considered to be low on responsiveness and high on demandingness, expecting children to accept regulations and rules without question and with complete obedience $^{(17)}$. In contrast, permissive parents are high on responsiveness but low on demandingness, setting few, if any, household rules and assigning few responsibilities 
to children ${ }^{(16)}$. Authoritative parents are high on both demandingness and responsiveness, explaining the reasoning behind rules and responsibilities and showing a willingness to consider their children's opinions ${ }^{(16)}$.

Research findings regarding the relationship between mothers' parenting style and child overweight/obesity have been mixed. For example, Rhee et al. ${ }^{(18)}$ ( $n$ 872, longitudinal design) found a positive association between child obesity and authoritarian, permissive and neglectful (parenting low in both warmth and control) parenting styles. Chen and Kennedy ${ }^{(19)}$ ( $n$ 163, cross-sectional design) found a positive relationship between permissive parenting (termed 'democratic' by the authors) and child weight but not between authoritarian parenting and child weight. Wake et $a l^{(20)}$ ( $n$ 4983, cross-sectional design) failed to find a relationship between parenting style and child overweight. Agras et $a l^{(21)}$ ( $n$ 150, longitudinal design) failed to find any significant associations between parenting styles and child weight.

The inconsistent findings for the association between parenting style and child obesity may be an indication that additional variables moderate this relationship ${ }^{(22)}$. In a recent review of the research literature on the association between parenting and child weight, Ventura and Birch $^{(10)}$ point out that an important step to advancing understanding of the parenting/child obesity association is to test for potential moderating influence. Such is the primary aim of the research discussed in the current report. We hypothesized that maternal depression and socio-economic status (SES) would moderate the permissive parenting/child obesity association and also the authoritarian parenting/child obesity association. The authoritarian and permissive parenting styles were specifically examined because of their negative effect on child functioning ${ }^{(23,24)}$ and because of the possible exacerbating influence that maternal depression and SES would have on these negative styles of parenting.

The permissive parenting style is associated with foodrelated parenting, specifically decreased parental awareness of and involvement in children's food choices ${ }^{(25,26)}$. Because maternal depression has been shown to be associated with lax and inconsistent disciplinary practices/rule enforcement $^{(23)}$, it may exacerbate the hands-off parenting style of permissive parents by further decreasing mothers' involvement in guiding children's healthy food choices. Higher SES, which is associated with increased allowance for child self-direction ${ }^{(27)}$ and the tendency to be more democratic $^{(28)}$ and indulgent ${ }^{(24)}$ in parenting, is likely to have a similar exacerbating influence on permissive parenting. The likely result is poorer child eating patterns and greater risk for child overweight/obesity. For example, given greater freedom over eating choices children may be more likely to eat while watching television, a practice associated with less healthful eating ${ }^{(29)}$.

The authoritarian parenting style, characterized by high demandingness and low emotional support, is associated with increased use of pressure and restriction in maternal feeding practices and decreased modelling of healthy eating behaviours for children ${ }^{(25)}$. Both maternal depression and low SES have been linked to parenting behaviours similar to those exhibited in the authoritarian parenting style. Maternal depression has been linked to decreased warmth and nurturance ${ }^{(30)}$, increased irritability and hostility ${ }^{(31)}$, and poor anger control towards children $^{(23)}$. Similarly, low SES parenting is associated with increased controlling behaviours, physical punishment, harsh discipline techniques ${ }^{(32)}$, and decreased use of reasoning ${ }^{(33)}$ and affection $^{(34)}$ with children. Thus, maternal depression and low SES may exacerbate the effects of authoritarian parenting on child weight by accentuating negative maternal feeding practices (i.e. pressure, restriction, failure to provide a positive model).

In sum, we tested four moderating hypotheses. First, maternal depression would exacerbate the impact of authoritarian parenting (H1) on child obesity. Second, maternal depression would exacerbate the impact of permissive parenting (H2) on child obesity. Third, low SES would interact with authoritarian parenting (H3) to increase risk for child obesity. Fourth, high SES would interact with permissive parenting (H4) to increase risk for child obesity.

\section{Method}

The participant sampling strategy was as follows: 597 families were recruited in autumn 2005; seven families moved in the same semester leaving a sample of 590. In spring 2006, questionnaire packets were distributed through the mail or schools to the 590 families for parents to complete; 253 (43\%) parents returned packets. A comparison of responders and non-responders revealed that children of non-responding mothers were slightly more likely to be obese than children of responding mothers $(16 \cdot 6 \% v \cdot 12 \cdot 6 \%)$. However, the difference was non-significant. Parents were paid \$US 20 for completing questionnaires. The protocol and procedures were approved by the university Institutional Review Board for Human Subjects and complied with the US Health Insurance Portability and Accountability Act guidelines protecting the privacy of health information.

Of the 253 families who returned parent questionnaires at baseline, 176 female caregivers (including 171 biological mothers as well as three stepmothers and two grandmothers identified as the primary female caregiver) for whom the following data were available were included in the study: at least one sub-scale of the parenting style measure (authoritarian or permissive, with the constraint that no more than one item be blank per sub-scale), a child's height and weight from which BMIfor-age percentile was calculated, and a score for SES and depression. For the sake of convenience, female 
caregivers will be referred to as 'mothers' throughout the paper. The only significant demographic difference between families who had complete data $v$. those who did not is that the former were more likely to be married.

Child measures were collected at all schools during the first four months of the child's first-grade year. Children's anthropometric assessments, including height and weight, were conducted by trained research assistants in the school gymnasium during a physical education period or in the hall outside the child's classroom. Training for research assistants prior to data collection followed guidelines set by the WHO Multicentre Growth Reference Study Group ${ }^{(35)}$. Research assistants practised measuring a standard person to within $0.5 \mathrm{~cm}$ and recording results accurately. During assessments, children were asked to remove bulky clothing (e.g. sweaters, jackets) and shoes before measurements. Children's body weight was determined by using a digital scale (Tanita electronic scale model BWB-800, accuracy $\pm 0 \cdot 2 \mathrm{lb}( \pm 0.09 \mathrm{~kg})$; Tanita, Arlington Heights, IL, USA). Height was measured with a portable height-measuring board, accuracy $\pm 0 \cdot 2 \mathrm{~cm}$ (Shorr Productions, Olney, MD, USA). Each child's height was measured twice and averaged for analysis. If the first two measurements were not within $\pm 0.3 \mathrm{~cm}$, a third height measurement was taken and the discrepant measure discarded.

The Demographic Questionnaire included questions covering parent and child age and ethnicity, as well as parent education, income and occupation. SES was computed from parent education and occupational status using the four-factor Hollingshead index ${ }^{(36)}$. Based on the Hollingshead criteria, scores were computed for parental occupational status and education and combined to form the SES score. In cases where SES scores were available for both parents, the mean was used. Possible SES scores range from 8 to 66 with scores corresponding to social strata (e.g. 30-39: skilled craftspeople, clerical and sales workers; 40-54: medium business, minor professionals and technical workers; 55-66: major business and professional).

The Parenting Styles and Dimensions Questionnaire $(\mathrm{PSDQ})^{(37)}$, a shortened version of the original sixty-twoitem questionnaire ${ }^{(38)}$, is a thirty-two-item instrument answered on a 5 -point scale $(1=$ never to $5=$ always $)$ and comprised of three scales measuring authoritarian (twelve items), authoritative (fifteen items), and permissive (five items) parenting. Authoritarian includes items such as 'I use physical punishment as a way of disciplining our child', 'I yell or shout when our child misbehaves' and 'I punish by taking privileges away from our child with little if any explanations'. Permissive reflects parents' lack of follow-through in discipline (e.g. 'I state punishments to our child and do not actually do them' and 'I find it difficult to discipline our child'). The PDSQ has been shown to be reliable and valid among preschool and school-aged children ${ }^{(39)}$. On the original shortened version, internal consistencies for the two parenting styles, authoritarian and permissive, were $0 \cdot 82$ and $0 \cdot 64$, respectively. Cronbach's $\alpha$ in the current sample was 0.75 for Authoritarian and 0.72 for Permissive. Scores were computed for each parenting style by calculating the mean of the items.

The Center for Epidemiologic Studies Depression Scale (CES-D) is a twenty-item, adult self-report instrument scored on a 4 -point $(0=$ rarely or none of the time to $3=$ most or all of the time) Likert-type scale that measures the degree to which participants have experienced depressive symptoms in the previous week ${ }^{(40)}$. Sample items include 'My sleep was restless', 'I felt lonely', 'I did not feel like eating' and 'I was bothered by things that usually don't bother me'. Internal consistency and testretest reliability of the CES-D have been shown to be within the acceptable range for samples that include women of the same age as the study participants ${ }^{(40)}$. Internal consistency in our sample was $\alpha=0 \cdot 90$. Scores were computed by calculating the sum of items resulting in a possible range of 0 to 60 .

BMI-for-age of the child participants was calculated using height, weight, sex and age. In order to calculate BMI-for-age, the child's sex, date of measurement, birth date, height and weight were entered into the Epi Info program $^{(41)}$. Child Obesity was defined as BMI-for-age $\geq 95$ th percentile ${ }^{(9,42)}$. The BMI-for-age percentiles were used to create a dichotomous variable with two levels, obese ( $\geq 95$ th percentile; $n$ 17) and non-obese $(<95$ th percentile; $n$ 159). The 95th percentile was used as the cutoff based on Krebs et al.'s ${ }^{(43)}$ identification that the specificity (i.e. the accurate exclusion of children who by the standard method for body fat assessment are not in the highest group) of the 95 th percentile cut-off ranges from $96 \%$ to $99 \%$, whereas the specificity of the 85 th percentile cut-off ranges from $67 \%$ to $96 \%$. Furthermore, the pattern of findings in the existing literature on the relationship between parenting style and child weight ${ }^{(18-20)}$ suggests that the 95th percentile is a more meaningful cut-off than the 85th percentile in examining this association.

Data were analysed using the SPSS statistical software package version $15 \cdot 0$ (SPSS Inc., Chicago, IL, USA). Multiple logistic regression analyses were conducted to test the four moderation hypotheses. Significance was set at $P \leq 0.05^{(44)}$. All regression models contained a main effect for a parenting style variable (Authoritarian or Permissive), a main effect for the moderator (Maternal Depression or SES) and the interaction term.

All continuous variables were centred (the mean of the variable was subtracted from each score) prior to creating the interaction term ${ }^{(45)}$. Post hoc probing was conducted to further examine significant moderator effects ${ }^{(45,46)}$. Interaction terms were created in accordance with steps outlined in Aiken and West ${ }^{(45)}$. In the case of SES, +1SD was used as high and -1 SD was used as low in accordance with Aiken and West's recommendation for continuous variables that do not have a clear high/low cut-off. In the case of depression, the cut-off of 16 identified by Beekman 
et $a l^{(47)}$ was used to classify mothers as Depressed ( $\left.n 36\right)$ or Non-Depressed ( $n$ 140) for follow-up analyses. The interaction terms were then computed by multiplying the new grouping variables (High or Low SES; Depressed or Non-Depressed) by Permissive or Authoritarian parenting style. Including more moderator variables (e.g. both SES and depression; marital status) in the logistic regression analyses produced essentially the same results as those of analyses with individual moderators. Thus, the more parsimonious models are presented in the results. Power calculations in logistic regression are incredibly complex and much work remains to be done ${ }^{(48)}$; we do however provide very preliminary power estimates based on Tosteson et al ${ }^{(49,50)}$ for the simple regressions that follow up on the significant interaction effects.

\section{Results}

A total of 176 mothers (including three stepmothers and two grandmothers identified as the primary female caregiver) of first-grade children (ninety-one boys, eighty-five girls) had complete data and were included in the present study. Sample characteristics are presented in Table 1. Mean BMIfor-age percentile of the children was $59 \cdot 97$ (SD 26.77). Means, standard deviations, and actual and possible ranges for all other measures in the study, including SES and Maternal Depression, are presented in Table 2. Preliminary analysis indicated that SES and Maternal Depression were not significantly correlated $(r=-0 \cdot 09, P=0 \cdot 62)$.

Results of logistic regression analyses testing $\mathrm{H} 1$ revealed no significant moderator effect of maternal depression on the relationship between Authoritarian parenting and Child Obesity (see Table 3 for all specific overall regression results). Tests of $\mathrm{H} 2$ revealed a significant moderator effect for Maternal Depression on the relationship between Permissive parenting and Child Obesity. Two separate post hoc logistic regression analyses were run; in the first, Depressed and Permissive, as well as their interaction, were entered. In the second, Non-Depressed and Permissive, as well as their interaction, were entered. Significance tests for the simple slopes of Permissive indicated that the simple slope for the Depressed regression line was significant, $\chi_{(1)}^{2}=3 \cdot 70$, $b=1.91, P=0.05, \quad$ OR $=6.74 \quad(95 \%$ CI $0.96,47 \cdot 16)$, power $=0 \cdot 88$. For each one-point increase in Permissive parenting among Depressed mothers, the odds of their children being obese increased by $6 \cdot 74$. For the NonDepressed line, the simple slope of Permissive was not significant, $\chi_{(1)}^{2}=0.33, \quad b=-0.31, \quad P=0.56, \quad \mathrm{OR}=0.74$ $(95 \%$ CI $0 \cdot 26,2 \cdot 09)$, power $=0 \cdot 33$; see Fig. 1 .

Results of logistic regression analyses testing $\mathrm{H} 3$ revealed no significant moderator effect of SES on the relationship between Authoritarian parenting and Child Obesity. Because interaction effects tend to be small, the power in the analyses may not have been sufficient to find significant
Table 1 Means and standard deviations or percentages for demographic measures in the study population: mothers and their first-grade children enrolled in rural public schools in a mid-western US state

\begin{tabular}{|c|c|c|c|}
\hline Variable & Mean or $\%$ & SD & $n$ \\
\hline Child's age (years) & $6 \cdot 85$ & $0 \cdot 37$ & 172 \\
\hline Mother's age (years) & $34 \cdot 91$ & $6 \cdot 31$ & 152 \\
\hline \multicolumn{4}{|l|}{ Child obesity* $(\%)$} \\
\hline No & $90 \cdot 3$ & & 159 \\
\hline Yes & $9 \cdot 7$ & & 17 \\
\hline \multicolumn{4}{|l|}{ Child's sex (\%) } \\
\hline Male & $51 \cdot 7$ & & 91 \\
\hline Female & $48 \cdot 3$ & & 85 \\
\hline \multicolumn{4}{|l|}{ Child's ethnicity (\%) } \\
\hline Euro-American & $77 \cdot 8$ & & 137 \\
\hline Native American & $18 \cdot 2$ & & 32 \\
\hline Multi-ethnic & $1 \cdot 7$ & & 3 \\
\hline Other minority & $1 \cdot 1$ & & 2 \\
\hline Not stated & $1 \cdot 1$ & & 2 \\
\hline \multicolumn{4}{|l|}{ Maternal ethnicity (\%) } \\
\hline Euro-American & $77 \cdot 8$ & & 137 \\
\hline Native American & $13 \cdot 6$ & & 24 \\
\hline Multi-ethnic & $4 \cdot 5$ & & 8 \\
\hline Other minority & $1 \cdot 7$ & & 3 \\
\hline Not stated & $2 \cdot 3$ & & 4 \\
\hline \multicolumn{4}{|l|}{ Maternal education (\%) } \\
\hline Less than 12th grade & $4 \cdot 6$ & & 8 \\
\hline High school diploma & $10 \cdot 8$ & & 19 \\
\hline Some colleget & $31 \cdot 6$ & & 55 \\
\hline Vo-tech graduate & $11 \cdot 9$ & & 21 \\
\hline College graduate & $40 \cdot 3$ & & 71 \\
\hline \multicolumn{4}{|l|}{ Marital status (\%) } \\
\hline Married, first time & $61 \cdot 4$ & & 108 \\
\hline Single, never married & $2 \cdot 8$ & & 5 \\
\hline Single, divorced & $10 \cdot 8$ & & 19 \\
\hline Remarried & $23 \cdot 9$ & & 42 \\
\hline
\end{tabular}

${ }^{*}$ Child obesity defined as BMI-for-age $\geq 95$ th percentile.

tAttended some college classes but did not graduate from college.

effects, and results for $\mathrm{H} 1$ and $\mathrm{H} 3$ should be interpreted cautiously. Tests of $\mathrm{H} 4$ revealed a significant interaction between Permissive and SES. Two separate post hoc regression analyses were run; in the first, High SES and Permissive as well as the interaction between them were entered. In the second, Low SES and Permissive as well as the interaction between them were entered. The simple slope for the High SES regression line was significant, $\chi_{(1)}^{2}=3 \cdot 80, b=1 \cdot 26, P=0 \cdot 05$, OR $=3 \cdot 51$ (95\% CI $0 \cdot 99$, 12.39), power $=0 \cdot 77$; whereas the simple slope for the Low SES regression line was not significant, $\chi_{(1)}^{2}=3 \cdot 12$, $b=-3 \cdot 71, \quad P=0.08, \quad$ OR $=0.02 \quad(95 \%$ CI $0 \cdot 00, \quad 1 \cdot 50)$, power $=0.99$. For mothers of higher SES, as Permissive parenting increased so did the odds of their children being obese (for each one point increase in Permissive the odds of their children being obese increased by 3.51 ); whereas, for mothers of lower SES, Permissive parenting was not significantly related to Child Obesity (see Fig. 2).

\section{Discussion}

The current study is the first to examine the moderating role of maternal depression and SES on the relationship 
Table 2 Means, standard deviations and ranges for study measures* among the study population: mothers and their first-grade children enrolled in rural public schools in a mid-western US state

\begin{tabular}{lcccc}
\hline Variable (questionnaire) & Scale mean & SD & Actual range & Possible range \\
\hline SES & $39 \cdot 00$ & $9 \cdot 88$ & $17-63$ & $8-66$ \\
Authoritarian (PSDQ) $\dagger$ & $1 \cdot 79$ & $0 \cdot 39$ & $1 \cdot 08-3 \cdot 50$ & $1-5$ \\
Permissive (PSDQ) $†$ & $2 \cdot 17$ & $0 \cdot 60$ & $1 \cdot 00-4 \cdot 20$ & $1-5$ \\
Maternal depression (CES-D) $\neq$ & $9 \cdot 58$ & $8 \cdot 40$ & $0-42 \cdot 00$ & $0-60$ \\
Child BMI percentile & $59 \cdot 97$ (median 64.71) & $26 \cdot 77$ & $0 \cdot 14-99 \cdot 81$ & $0-100$ \\
\hline
\end{tabular}

SES, socio-economic status; PSDQ, Parenting Styles and Dimensions Questionnaire; CES-D, Center for Epidemiologic Studies Depression Scale. *Sample size $(n)$ for statistics ranges from 171 to 176

tAll PSDQ scales: $1=$ never, $2=$ once in awhile, $3=$ about half the time, $4=$ very often, $5=$ always.

fCES-D scale: $0=$ rarely, $1=\mathrm{a}$ little of the time, $2=$ occasionally, $3=$ most of the time.

Table 3 Regression analyses predicting child overweight among first-grade children enrolled in rural public schools in a mid-western US state

\begin{tabular}{|c|c|c|c|c|c|c|c|c|}
\hline \multirow{2}{*}{$\begin{array}{l}\text { Outcome } \\
\text { Predictors }\end{array}$} & \multicolumn{3}{|c|}{ Model summary } & \multicolumn{3}{|c|}{ Coefficients } & \multicolumn{2}{|c|}{$95 \% \mathrm{Cl}$ for OR } \\
\hline & $C^{2}$ & df & $P$ & $B$ & SE & OR & Lower & Upper \\
\hline Overall & $3 \cdot 82$ & 3 & $0 \cdot 28$ & & & & & \\
\hline Authoritarian & $3 \cdot 05$ & 1 & 0.08 & $-1 \cdot 58$ & 0.44 & $0 \cdot 21$ & 0.04 & $1 \cdot 18$ \\
\hline Depression & $0 \cdot 36$ & 1 & 0.55 & 0.02 & 0.04 & $1 \cdot 02$ & 0.96 & $1 \cdot 09$ \\
\hline Authoritarian $\times$ Depression & $0 \cdot 70$ & 1 & $0 \cdot 40$ & 0.06 & 0.05 & $1 \cdot 06$ & 0.92 & $1 \cdot 21$ \\
\hline Overall & $4 \cdot 74$ & 3 & $0 \cdot 22$ & & & & & \\
\hline Permissive & 0.394 & 1 & 0.44 & 0.277 & 0.44 & $1 \cdot 30$ & $0 \cdot 60$ & $3 \cdot 41$ \\
\hline Depression & 1.075 & 1 & 0.04 & -0.042 & 0.04 & 0.96 & 0.90 & $1 \cdot 04$ \\
\hline Permissive $\times$ Depression & $3 \cdot 814$ & 1 & 0.05 & 0.087 & 0.05 & $1 \cdot 09$ & $1 \cdot 00$ & $1 \cdot 19$ \\
\hline Overall & $4 \cdot 02$ & 3 & $0 \cdot 26$ & & & & & \\
\hline Authoritarian & $2 \cdot 42$ & 1 & $0 \cdot 12$ & $-1 \cdot 04$ & 0.90 & $0 \cdot 25$ & 0.04 & $1 \cdot 44$ \\
\hline SES & $0 \cdot 38$ & 1 & 0.54 & 0.02 & 0.03 & $1 \cdot 02$ & 0.96 & $1 \cdot 08$ \\
\hline Authoritarian $\times$ SES & 0.93 & 1 & $0 \cdot 34$ & 0.08 & 0.09 & $1 \cdot 09$ & 0.92 & $1 \cdot 29$ \\
\hline Overall & $4 \cdot 56$ & 3 & 0.21 & & & & & \\
\hline Permissive & 0.91 & 1 & $0 \cdot 31$ & 0.42 & 0.44 & $1 \cdot 52$ & 0.64 & $3 \cdot 61$ \\
\hline SES & $0 \cdot 25$ & 1 & $0 \cdot 61$ & 0.01 & 0.03 & $1 \cdot 01$ & 0.93 & $1 \cdot 07$ \\
\hline Permissive $\times$ SES & $3 \cdot 87$ & 1 & 0.05 & 0.09 & 0.04 & $1 \cdot 08$ & $1 \cdot 00$ & $1 \cdot 18$ \\
\hline
\end{tabular}

$B$, non-standardized regression coefficient; SE, standard error of $B$; SES, socio-economic status.

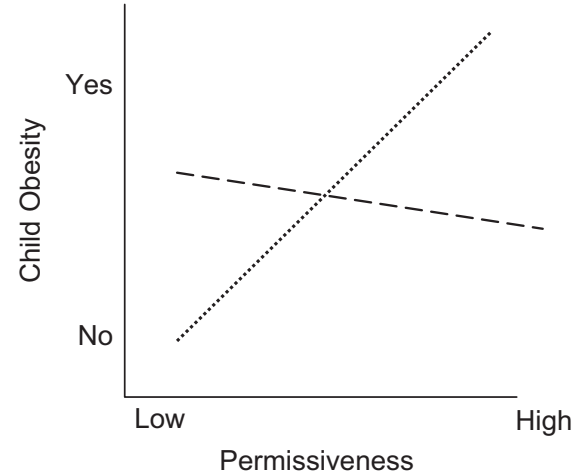

Fig. 1 Depiction of the moderating effect of maternal depression on the relationship between permissiveness and child overweight, illustrating a significant slope for Depressed $(\cdots)$ and a non-significant slope for Non-Depressed (- - -) mothers

between parenting style and child obesity. Both maternal depression and SES were found to moderate the permissive parenting/child obesity association. The finding that the interaction between maternal depression and permissive parenting increased the likelihood of child obesity may be a function of the fact that both are likely

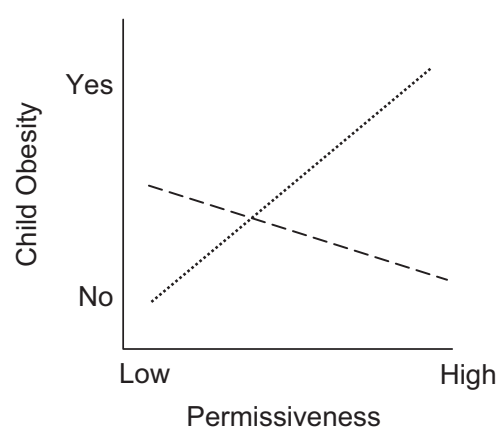

Fig. 2 Depiction of the moderating effect of socio-economic status (SES) on the relationship between permissiveness and child overweight, illustrating a significant slope for High SES $(\cdot \cdot)$ and a non-significant slope for Low SES (- - -) mothers

to reduce maternal involvement in guiding the child's healthy food choices. Furthermore, both maternal depression and permissive parenting tend to undermine child self-regulation $^{(51,52)}$ and, thus, may leave children with few internal resources to help them regulate their own patterns of dietary intake. The combination of limited child internal regulation (i.e. self-regulation) with 
decreased external regulations (i.e. maternal monitoring behaviours) may be particularly problematic to the development of healthy eating patterns among children. Future research is needed to examine the possibility that parent feeding practices and child self-regulation mediate the impact of the interaction of maternal depression and permissive parenting on child obesity.

The finding that the interaction between high SES and permissiveness increases the risk for child obesity may be partially explained by research suggesting that high SES parents tend to be more indulgent in their parenting ${ }^{(24)}$. The combination of high SES and permissive parenting may result in a particularly indulgent parenting style that fails to help children develop self-regulation in general and specifically with decisions related to eating. It is unclear, however, why authoritarian parenting did not interact with either SES or maternal depression in predicting child obesity. The restricted range of scores on the authoritarian parenting variable (none of the mothers scored above 3.5 on the 5 -point scale) may help explain the absence of findings here. It should also be reiterated that the sample size needed to detect small effects is often quite large, and interaction effects are typically smaller than main effects ${ }^{(53)}$, thus lack of power may have been a factor in our non-significant findings.

There were several limitations in the current study. Similar to much of the previous research examining the link between parenting style and child obesity, the design of the present study was cross-sectional, making it difficult to draw definitive conclusions about whether the interaction of permissiveness with other risk factors leads to child obesity, or whether child eating patterns or child body weight lead to maternal permissiveness and depression. Future research should utilize a longitudinal design to further explore the nature of these relationships. The $43 \%$ response rate was an additional limitation but is consistent with other studies employing a similar survey methodology ${ }^{(54,55)}$. As mentioned in the Methods section, children of non-responding mothers were slightly more likely to be obese than children of responding mothers $(16.6 \% \mathrm{v}$. $12.6 \%)$. Although the absence of a statistical difference in response rate between parents of obese and non-obese children alleviates concern about bias in the sample, the comparatively smaller percentage of obese children in the sample is considered a limitation because obese children were of particular interest in the study. Finally, the sample was primarily Euro-American with Native Americans comprising the second most common ethnic group. Due to the important association between ethnicity, parenting style and overweight/obesity ${ }^{(56,57)}$, further research is warranted in order to explore the relationship between parenting style and child obesity, and the moderating effects of maternal depression and SES, in large samples of parents and children of specific ethnic backgrounds.

The results of the present study contribute to the existing knowledge of parenting influences on child obesity. The study is unique in that it sheds light on the moderating influence of two family risk factors, maternal depression and SES, on the link between parenting style and child obesity. The study also makes an important contribution to the literature by examining the association between parenting style and child obesity in a relatively large, low-income, rural population of school-aged children and their mothers, a population under-represented in child overweight/obesity research ${ }^{(10)}$.

The results of the present study provide support for calls to broaden child obesity prevention and treatment programmes to address non-food-related parenting. Should further studies confirm the current results, it would be important for those working with children and parents to help mothers who exhibit permissive parenting styles (especially higher SES or depressed mothers) learn to be more structured in their limit setting and follow through with their children, in both food-related and non-foodrelated situations. Further research utilizing a longitudinal design is needed to provide additional evidence of the associations found in the current study.

\section{Conclusions}

Maternal depression and SES moderated the association between permissive parenting and child obesity. For depressed mothers, permissive parenting was predictive of child obesity. Likewise, for high SES mothers, permissive parenting was predictive of child obesity. The results provide insight into the complex association between parenting style and child obesity and overweight and have potential to inform treatment and prevention programmes for child obesity. Longitudinal research is needed to further test the relation among these variables.

\section{Acknowledgements}

Source of funding: This research was supported by United States Department of Agriculture Grant 2004-05545. Conflict of interest declaration: No conflicts of interest exist. Authors' contributions: study plan and design (A.W.H., T.S.K., G.L.T., M.C.P., L.H.-T.); data collection (A.W.H., J.M.R., T.S.K., G.L.T., M.C.P., L.H.-T.); data analysis (M.C.P.); writing of the paper (G.L.T., M.C.P., A.W.H., L.H.-T., J.M.R.); critical review of the paper (L.S.). Acknowledgements: We would like to thank all of the participating parents and children. We would also like to extend special thanks to Tracey Ledoux and Aimee Barrett for the key role they played in ongoing data collection and project management.

\section{References}

1. Anderson PM \& Butcher KF (2006) Childhood obesity: trends and potential causes. Future Child 16, 19-45. 
2. Gable S \& Lutz S (2000) Household, parent, and child contributions to childhood obesity. Fam Relat 49, 293-300.

3. World Health Organization (1998) Obesity: Preventing and Managing the Global Epidemic. Geneva: WHO.

4. Lobstein T, Baur L \& Uauy R (2004) Obesity in children and young people: a crisis in public health. Obes Rev 5, Suppl. 1, 4-104.

5. Ogden CL, Carroll MD \& Flegal KM (2008) High body mass index for age among US children and adolescents, 2003-2006. JAMA 299, 2401-2405.

6. Daniels SR (2006) The consequences of childhood overweight and obesity. Future Child 16, 47-67.

7. Davison KK \& Birch LL (2001) Weight status, parent reaction, and self-concept in five-year-old girls. Pediatrics 107, 46-53.

8. Young-Hyman D, Tanofsky-Kraff M, Yanovski SZ et al. (2006) Psychological status and weight-related distress in overweight or at-risk-for-overweight children. Obesity $\mathbf{1 4}$ 2249-2258.

9. Krebs NF, Himes JH, Jacobson D et al. (2007) Assessment of child and adolescent overweight and obesity. Pediatrics 120, Suppl. 4, S193-S228.

10. Ventura AK \& Birch LL (2008) Does parenting affect children's eating and weight status? Int J Behav Nutr Phys Act 5, 15-27.

11. Bosch J, Stradmeijer M \& Seidell J (2004) Psychosocial characteristics of obese children/youngsters and their families: implications for preventive and curative interventions. Patient Educ Couns 55, 353-362.

12. Gilles AE, Cassano M, Shepherd EJ et al. (2008) Comparing active pediatric obesity treatments using meta-analysis. J Clin Child Adolesc Psychol 37, 886-892.

13. Golan M \& Crow S (2004) Targeting parents exclusively in the treatment of childhood obesity: long-term results. Obes Res 12, 357-361.

14. Kitzmann KM \& Beech BM (2006) Family-based interventions for pediatric obesity: methodological and conceptual challenges from family psychology. J Fam Psychol 20, 175-189.

15. Rhee K (2008) Childhood overweight and the relationship between parent behaviors, parenting style, and family functioning. Ann Am Acad Polit Soc Sci 615, 12-37.

16. Baumrind D (1966) Effects of authoritative parental control on child behavior. Child Dev 37, 887-907.

17. Aunola K, Stattin H \& Nurmi JE (2000) Parenting styles and adolescents' achievement strategies. I Adolesc 23 , 205-222.

18. Rhee KE, Lumeng JC, Appugliese DP et al. (2006) Parenting styles and overweight status in first grade. Pediatrics 117, 2047-2054.

19. Chen J \& Kennedy C (2004) Family functioning, parenting style, and Chinese children's weight status. J Fam Nurs 10 , 262-279.

20. Wake M, Nicholson JM, Hardy P et al. (2008) Preschooler obesity and parenting styles of mothers and fathers: Australian national population study. Pediatrics 120 , $1520-1527$.

21. Agras W, Hammer L, McNicholas F et al. (2004) Risk factors for childhood overweight: a prospective study from birth to 9.5 years. J Pediatr 145, 20-25.

22. Baron RM \& Kenny DA (1986) The moderator-mediator variable distinction in social psychological research: conceptual, strategic, and statistical considerations. J Pers Soc Psychol 51, 1173-1182.

23. Johnson JG, Cohen P, Kasen S et al. (2001) Association of maladaptive parental behavior with psychiatric disorder among parents and their offspring. Arch Gen Psychiatry 58, 453-460

24. Glasgow KL, Dornbusch SM, Troyer L et al. (1997) Parenting styles, adolescents' attributions, and educational outcomes in nine heterogeneous high schools. Child Dev 68, 507-529.

25. Hubbs-Tait L, Kennedy TS, Page MC et al. (2008) Parent feeding practices predict authoritative, authoritarian, and permissive parenting styles. J Am Diet Assoc 108, 1154-1161.

26. Blisset J \& Haycraft E (2008) Are parenting style and controlling feeding practices related? Appetite 50, 477-485.

27. Tudge JRH, Hogan DM, Snezhkova IA et al. (2000) Parents' child rearing values and beliefs in the United States and Russia: the impact of culture and social class. Infant Child Dev 9, 105-121.

28. Hoffman ML (1963) Personality, family structure and social class as antecedents of parental power assertion. Child Dev 34, 869-884.

29. DuBois L, Farmer A, Gerard M et al. (2008) Social factors and television use during meals and snack is associated with higher BMI among preschool children. Public Health Nutr 11, 1267-1279.

30. Beardslee WR, Bemporad J, Keller MB et al. (1983) Children of parents with major affective disorder: a review. Am J Psychiatry 140, 825-831.

31. Downey G \& Coyne JC (1990) Children of depressed parents: an integrated review. Psychol Bull 108, 50-76.

32. Lempers JD, Clark-Lempers D \& Simons RL (1989) Economic hardship, parenting, and distress in adolescence. Child Dev 60, 25-39.

33. Whitbeck LB, Simons RL, Conger RD et al. (1997) The effects of parents' working conditions and family economic hardship on parenting behaviors and children's selfefficacy. Soc Psychol Q 60, 291-303.

34. Simons RL, Lorenz FO \& Conger RD (1992) Support from spouse as mediator and moderator of the disruptive influence of economic strain on parenting. Child Dev 63 , 1282-1301.

35. World Health Organization Multicentre Growth Reference Study Group (2006) Reliability of anthropometric measurements in the WHO Multicentre Growth Reference Study. Acta Paediatr 450, 38-46.

36. Hollingshead AB (1975) Four-factor index of social status. Working Paper. New Haven, CT: Yale University.

37. Robinson CC, Mandleco B, Olsen SF et al. (2001) The Parenting Styles and Dimensions Questionnaire (PSDQ). In Handbook of Family Measurement Techniques. vol. 3: Instruments and Index, pp. 319-321 [BF Perlmutter, $\mathrm{J}$ Touliatos and GW Holden, editors]. Thousand Oaks, CA: Sage.

38. Robinson CC, Mandleco B, Olsen SF et al. (1995) Authoritative, authoritarian, and permissive parenting practices: development of a new measure. Psychol Rep 77, 819-830.

39. Porter CL, Hart CH, Yang C et al. (2005) A comparative study in child temperament and parenting in Beijing, China and the western United States. Int J Behav Dev 29, 541-551.

40. Radloff LS (1977) The CES-D Scale: a self-report depression scale for research in the general population. Appl Psychol Meas 1, 385-401.

41. Centers for Disease Control and Prevention (2009) What is Epi Info ${ }^{\mathrm{TM}}$ ? http://www.cdc.gov/epiinfo (accessed November 2009).

42. Centers for Disease Control and Prevention (2009) About BMI for Children and Teens. http://www.cdc.gov/ nccdphp/dnpa/bmi/childrens_BMI/about_childrens_BMI.htm (accessed November 2009).

43. Krebs NF, Himes JH, Jacobson D et al. (2007) Assessment of child and adolescent overweight and obesity. Pediatrics 120, 193-228.

44. American Psychological Association (2001) Publication Manual of the American Psychological Association. Washington, DC: APA. 
45. Aiken LS \& West SG (1991) Multiple Regression: Testing and Interpreting Interactions. Thousand Oaks, CA: Sage.

46. Holmbeck GN (2002) Post-hoc probing of significant moderational and mediational effects in studies of pediatric populations. J Pediatr Psychol 27, 87-96.

47. Beekman ATF, Deeg DJH, van Limbeek J et al. (1997) Criterion validity of the Center for Epidemiologic Studies Depression scales (CES-D): results from a communitybased sample of older subjects in the Netherlands. Psychol Med 27, 231-235.

48. Hsieh FY, Bloch DA \& Larson MD (1998) A simple method of sample size calculation for linear and logistic regression. Stat Med 17, 1623-1634.

49. Tosteson TD, Buzas JS, Demidenko E et al. (2003) Power and sample size calculations for generalized regression models with covariate measurement error. Stat Med 22, 1069-1082.

50. Tosteson TD, Buzas JS, Demidenko E et al. (2009) Power calculations for logistic regression with exposure measurement error. http://biostat.hitchcock.org/MeasurementError/ Analytics/PowerCalculationsforLogisticRegression.asp (accessed November 2009).
51. Baumrind D (1989) Rearing competent children. In Child Development Today and Tomorrow, pp. 349-378 [W Damon, editor]. San Francisco, CA: Jossey-Bass.

52. Cummings EM, Davies PT \& Campbell SB (2000) Developmental Psychopathology and Family Process: Theory, Research, and Clinical Implications. New York: Guilford Press.

53. Cohen J, Cohen P, West SG et al. (2003) Applied Multiple Regression/Correlation Analysis for the Behavioral Sciences, 3rd ed. Mahwah, NJ: Erlbaum.

54. McFarlane E, Olmsted MG, Murphy J et al. (2007) Nonresponse bias in a mail survey of physicians. Eval Health Prof 30, 170-185.

55. VanHorn PS, Green KE \& Martinussen M (2009) Survey response rates and survey administration in counseling and clinical psychology: a meta-analysis. Educ Psychol Meas 69, 398-403.

56. Cullen KW, Baranowski T, Owens E et al. (2002) Ethnic differences in social correlates of diet. Health Educ Res 17, 7-18.

57. Haas JS, Lee LB, Kaplan CP et al. (2003) The association of race, socioeconomic status, and health insurance status with the prevalence of overweight among children and adolescents. Am J Public Heath 93, 2105-2110. 